\title{
Library Digitization: The Niia Experience, Lessons Learn't And Way Forward
}

\author{
Pamela Ogwuazor Momah \\ A Librarian with the Nigerian Institute of International Affairs (NIIA) Lagos.
}

\begin{abstract}
This article takes a look at the growing digital environment and how Libraries through digitization are able to brigade the digital divide between information and knowledge, thereby allowing the library to engage new user communities, while being able to reach a global audience. The NIIA Library, a leader in new Library innovations has also joined the band wagon in using this new innovative approach to Librarianship. In 2006, it started its digitization project with its Press Library collection. The article examines NIIA digitization project, the hitches it faced, lessons learnt and the way forward.
\end{abstract}

Key Words: Digitization: Digital Divide: Information and Knowledge: Innovation

\section{Introduction}

According to Daly and Organ, 2014, "The digital environment is growing rapidly, through ubiquitous and increasingly powerful personal computing devices and the demand for information to accessible Libraries and archives, as traditional providers and storehouses of content, are adapting to this changing environment by adopting new and innovative digital delivery mechanism" 1 .With the advent of ICT and its application to Librarianship, the delivery of Library services to the users has taken another form. Libraries are institutions known for holding information and knowledge for users. They house the materials and provide the physical space, in a conducive atmosphere that allows for research and educational activities to be carried out. ICT has allowed for information to be repackaged by Library professionals, in such a way that it can reach a larger audience, instantaneously. According to Ayanbode, 2."---the advent of the internet and the ability to digitize large quantities of text and images and make them available over the web has transformed ways (Libraries) working". He also says that Libraries are now facilitators in this digital age. The Library is not now only a building housing books and materials, waiting for users to com and use, it has metamorphosed into a place where the information and knowledge divide is bridge through digitization. Ayanbode, 3, says that "Digitization for these purposes enables the Library to engage new user communities and target a range of audience, using innovative approaches"

\section{What Is Digitization And Digital Library}

Library Digitization is the use of technology in collecting, storing, organizing, and preserving of Library resources. This entails the conversion of library hard copies to electronic copies. In 2009, the National Library of Australia, 4. Stated that "Digitization is a process of creating digital surrogate collection", according to them to them this involves capturing, storage, management and long term preservation. Digitization is a process, it can take the form of analogue materials being converted to digital materials or the material being "born" digital from the beginning While, the terms, Digital Library, electronic Library or E-Library ,Virtual Library are Institutions where the resources are E-resources, that needs computers to be able to access the information. These are all types of information retrieval systems. When talking about digital format or Eresources, there are some digital content that were created digital and others that were analogue originally, and then are converted to digital format. When these two format s exist side by side in the Library, the Library is said to be a hybrid Library.

\section{Advantages Of Digitization}

(1) There is no physical boundary or limitation, once a material is in digital format. The material can be easily sent by e-mail to a user. The user can easily access it from anywhere over the web.

(2) A digital resource can be used by many people simultaneously. There is no need to wait for the borrower of a book to bring it back, before another user can have access to it.

(3) A digital resource can be used 24 hours, seven day a week. Opening hours of the Library does not present a problem, once the user has internet connectivity. So if a user decides to use the material by $2.00 \mathrm{am}$, he can.

(4) Most Libraries have to constantly weed its collection to make room for new stock. This is very necessary because of the problem of lack of space. Digital material does not take up space as quickly as analogue materials. Thus question of lack of space is minimized. 
(5) Books and analogue materials tend to get thorn due to much usage, or mutilated by bad Library users, or stolen by selfish users or they just slowly disintegrate due to age. Digitization puts the materials on cyber space, where none of above mentioned things can negatively affect the materials. Digitization therefore is a very good form of protecting and preserving Library materials

(6) Digitization encourages sharing, exchanging information and Knowledge.Libaries and Library professional can collaborate. Research findings can be easily and instantaneously shared by professional collegues. There is no need to travel long distances to get required information.

\section{Disadvantages Of Digitization}

(1) The main problem with digitization is Systems problems. Newer versions of Computer software's are always coming out, making the other obsolete. There is as constant need to updater to a newer version, so as to fix bugs and increase speed etc. If there is no systems person or the Librarian is not a systems Librarian the people making use of the system, most of the time do not have the capacity to do theses maneuvers that are necessary to keep the systems working at its full capacity. The system becomes slow and may refuse to open some documents.

(2) Proper and high speed inert connectivity is a big problem, especially in the developing world. The internet service providers tend to have one thing or the other happening to it. When this I the case access to materials over the net is denied.

(3) The epileptic light situation does not help matters. Most of the time diesel is used to run the office. The high cost of diesel makes the electronic Library a very expensive venture. Thus maintaining a digitized collection is capital intensive.

(4) More money is required for a digital collection. Trying to convince management to give more money, in the face of budget cut backs is a very difficult task.

(5) In a developing country like Nigeria, where the majority of the people in the rural areas have no access to internet; those places are automatically cut off, basically because of lack of infrastructure. In the urban areas the majority of the people depend on going to the cyber café, for internet access. There is, however, an increase in those with personal computers, android phones, tablets and Ipads, but still compared to the people who do not have these gadgets, there are in the minority.

(6) These computer hardware's and software, need a conducive, cool environment, to work optimally. A lot of times what happens is that for one or the other, electricity, lack of enough diesel, the Library environment is not as cool as it should be. This leads to a lot of software and hardware problems.

\section{Standards Of Digital Content}

There is a need for NIIA to adopt polices regards the standards, selection and preservation of digitized materials. NIIA Library is one that has collaborative agreement with some institutions and is planning to have more of such agreements with leading Libraries worldwide; there is therefore a need for the digitized files to meet international accepted standards. This will allow easy cross searching and integration. The MARC standard, which is a standard interchange format for representing catalogue records electronically, would be a good standard to adopt. As regards copyright of digitized materials, since electronic data are easily duplicated and redistributed, there needs to be a copyright that is realistic. This can take the form of a written permission, which allows a person to use the work for academic purposes only, while given credit to the creator of the work.This law will be in respect of those digital works that belongs to NIIA, and we created ourselves.eg.NIIA books, journals, videos and photographs. According to Hazen, 1998, 5. materials protected by copyright in the Library which has been digitized, with the appropriate permission secured from the owners of the work, can be circulated for academic purposes.

\section{Brief History Of The NIIA Library}

The Nigerian Institute of International Affairs was established in 1963 as an independent non-official, non-political and non-profit making organization. In August 1971, the Institute was taken over by the Nigerian government, but its character as an independent, non-political and non-profit making organization remains unchanged. The Act setting up the Institute, NIIA Act 1971 Cap.311, provided for the setting up of a Library that would provide the tools which would be used to achieve the goals of the Institute. The 1986 amendment no.16, section 14 subsection (1) and (2), respectively talks the books and publications that should be in the Library and the fact that a certified true copy of every treaty entered into by the Federal Republic of Nigeria, shall be deposited in the Library.

\section{NIIA Library Collection}

The collection is mainly in the field of the social sciences, with basic materials on the UN, IMF, World Bank, FAO, UNESCO etc. Documents of foreign governments, international treaties and conventions, 
agreements and treaties entered into by Nigeria. The Library is a depository of UN, World Bank, AU, and ECOWAS. Oral documentation tapes, with interviews of distinguished Nigerians who have played a leading role in Nigeria's foreign policy, these form the audio visual archives, and are housed in the Library. There also e-resources, the NIIALOC; the on-line Library catalogue, EBSCO and JSTOR o-line data base and various CD ROM's and electronic versions of subscribed journals, which accompany the journals. There is a rich and large photograph collection. Pictures dating back to pre-independence days till the present time. There is a Library within-a-Library, known as the Press Library, which mainly consists of Newspaper clippings from Nigerian and Foreign Newspapers, conference papers and pamphlets. These are classified under given subject headings and filed away in cabinet files under that subject.

\section{NIIA Computerization and Digitization Project}

Computerization of the NIIA Library started in 1991, with the 1990 acquisitions. Card catalogues cabinets were replaced with computer terminals that provided on-line access. As a result of this automation various Library operations became much easier, 6 . Since then the Tin-LiB Library software, Alice Library software, and Liberty Library software have been used to house the Library records electronically. Computerization was the first step in the digitization process. In 2006 the Library decided to digitize the Press Library collection. Depending on the success of this exercise other materials, would be digitized.eg, NIIA publications, and photographs. For us this would be a good learning experience.

\section{The Press Library-Digitization}

The Press Library is made up of clippings, both from local and foreign Newspapers. These clippings cover local and international issues as they relate to Nigeria. It is a very important collection, because most times, breaking news can only be found in the Newspapers. It would take some time for the subject matter to evolve and become a topic that can be found in books and journals. Thus the Press Library is a haven for Researchers, both local and international, who need urgent information on such topical issues. That is why it was decided that to start with this collection was appropriate.

Thus in 2006 the Library management decided to ask DocuTrust Nigeria Limited to do a demo, for us to see. Two subject areas were chosen, Nigerian Boundaries- Cameroon and Nigerian Foreign Policy. The files were given to them. From the demo, we liked what we saw. The company wanted us to buy their own Library software, but this was not what we really wanted to do, as we had our own Alice Library software we were using at the time. The Problem with Alice was it was although it was window based software, it was not web based. Another militating factor was that of lack of funds. This led to the stalling of the digitization project. In the meantime the Press Library staffs were told to go to the on-line versions of the local Newspaper and to copy and paste and save the article on Microsoft word, until a time when the article would be uploaded to the electronic catalogue. The problem we encountered was that after a while the saved articles refused to open, and the whole exercise was in vain. This happened due to software problems, which was not managed well by the staff involved, who were systems people.

Then in 2010 the problem was revived again. This time Templeton Business Solutions, a company offering electronic document management, digitization and data capture services, professional advice on records management, business systems and custom software development. The staff had to first of all tidy the file, sort out and arrange the files properly. Then the chosen 100,000 clippings on the heavily used subject areas were handed over to Templeton. They scanned the materials into a disc over a period of some months. They were expecting to use their own data base, but that was not what we wanted. They did not asses the work very well because at this point they were asking for more money as we wanted the work to be indexed to our NIIALOC. They expected that would hand over a disc of the digitized material. On the disc a lot of fields were missing. Such fields as you would find in a Library catalogue e.g. pages, notes, physical description etc. They had just straight scanning. They were not Librarians and indexing the material into our data base was well over their heads. This caused a bit of a misunderstanding and stalled the work as they said that continuing without more money added to their fees, would be suicidal for them. The fees were eventually reviewed a bit upwards, but though they tried indexing the material, what they did was still not what we wanted. They had misunderstood what we really wanted and thus had under quoted. At this point we decided to cut our losses we contacted the Sotflink vendor in Nigeria at the time and he helped to do a lot of mistakes and to put in the form that would suit our Library needs. After this he sent the work off to Softlink in the UK the manufacturers of Liberty Library software and they indexed the work into the NIIA Library catalogue.

There is still that has to be digitized, but money is one militating factor. The Library management now decided that the back log would be tackled later on future. Meanwhile everyday instead of cutting the selected article and mounting it and filing away in the files put in file cabinets, the officer in charge goes straight to the on-line version of the news article. This is copied and pasted on Microsoft word, with all the necessary information, eg. Author, title, date, and page. When this is done the officer now indexes this information into the 
NIIA Library catalogue. This immediate upload ensures that the document does not get corrupted and refuses to open, as was the case the first time it was done. More training was given to the Press Library staff, so that they are now more comfortable in doing this job. As for the back log, its either we buy our own scanners or we lease scanners, and scan the materials, save as word documents and upload into the on-line catalogue. The other materials to be digitized consist of NIIA publications, conference papers, books and journals. The management is thinking of doing the job in-house. This means that the staff will have to receive proper training. The staff doing the job has its own advantage, in that they know exactly what they want to see in the finished product and there would not be too many mistakes in the catalogue.

\section{Lessons Learnt And Recommendations}

A few lessons were learnt from NIIA digitization of the Press Library. These lessons will help guide in future digitization efforts of the Library.

(1) When hiring a digitization company to digitize Library materials, one has to bear in mind the unique nature of a Library catalogue and its features. The people doing the work must have a Library background and they must have the ability to index the digitized work into the Library's on-line catalogue. That's people who do Library digitize specifically must be chosen for the work.

(2) The scope of the work to be done must be very clear to the contractor, so that the price quoted for the work will not need an upward review.

(3) The end product has to look good and not faded and disorderly. Maybe this would involve touching up the old and faded clippings, before it is digitized and uploaded into the catalogue.

(4) There is need for all the Library staffs who are working in that section to be fully carried along. They should be able to ask questions and see what is being done. By so doing certain misunderstandings can be avoided, before the mistake gets too much. There is a need to send the staff for training. This can be done by sending them to digitization workshops.

(5) For maximum efficiency the digitization project manager should be different from the Librarian in charge of the section/division being digitized. This is because the Librarian already has to supervise the day to day running of the affairs of the division, and to add digitization to the schedule would be too much.

(6) The physical files that have already been digitized should not be easily discarded. Light and internet connectivity can act up, and resorting to the physical file would be the only way to access information.

\section{Conclusion}

In this ICT era one can see that information in the Libraries are being repackaged and put into different format, so as to reach a wider audience instantaneously. Library digitization provides the bridge for the information and knowledge divide in this digital age. There are no more physical and geographical boundaries. Multiple users at different points can make use of the material at the same time, it can be accessed any time, and there is no question of the Library being closed or public holidays. Space is no longer a problem as materials are held in cyberspace, thus allowing for more efficient space management. Preservation from theft, mutilation is enhanced by digitization. Miss shelving, whether mistakenly or purposely are things of the past with digitization. Information and knowledge is easier to be shared more meaningfully and more exchanges and collaborative efforts between institutions are made much more easier with digitization

\section{References}

[1]. Daly, Rebecca and Organ Michael.(2014).Embed and Engage! Delivering a digitization program at the University of Wollongong Library. Australian Library Journal.Vol.63,Issues 3.p.220

[2]. Ayanbode, Oluyemi, (2011).Library Digitization A Strategy to Bridge Information and Knowledge Divides. European Journal of Scientific Research. Vol.56,No.2.p.212

[3]. Ibid:p.213 p.213 2011

[4]. National Library of Australia .(2009).Collection Digitization Policy.www.nla.au/policy/digitization.html

[5]. Oni, J.A. (1995) Computers in Libraries: Awareness and Application .Proceedings of National Workshop on Computerization of NIIA Library.Lagos.NIIA.

[6]. Hazen,Dan, Horell Jeffrey and Merrill-Oldham.(1998) Selecting Research Collection for Digitization. Washington ,D.C. Council for Library and Information Research .http://www.clir.org/Pub/reports/hazen/pub74.html 